\title{
ANALYSIS OF THE DETERMINANTS OF THE PERFORMANCE OF INVESTMENT PROJECTS FINANCED BY THE WORLD BANK IN WAEMU COUNTRIES: AN ECONOMETRIC APPROACH
}

\author{
Rémy Hounsou, Ph. D.
}

Ecole Nationale d'Economie Appliquée et de Management (ENEAM), Université d'Abomey Calavi, BENIN

DOI: http://dx.doi.org/10.38193/IJRCMS.2021.3506

\begin{abstract}
This study analyzes the determinants of the performance of investment projects financed by the World Bank in the WAEMU countries. A descriptive analysis and an econometric analysis based on the estimation of a probit model have been developed. Results concerning data relating to 225 projects covering the period 2002 - 2019 show that, on the one hand, the model is globally and statistically significant, and on the other hand, the performance of the projects is influenced by the duration of the project, the amount allocated to the project, the nature of the project, the efficiency of the government and the growth rate of real GDP per capita. Also, our empirical study suggests to the investors, mainly to the World Bank that the longer duration of a project allows adjustments to be made which improve project performance and that large-scale projects are the most efficient.
\end{abstract}

KEYWORDS: performance; investment project; WAEMU; World Bank

JEL: C12; F21; F36; O19

\section{INTRODUCTION}

Public development aid (PDA) is a source of development financing and remains essential for African countries which still facing budget constraints and a lack of capacity to develop and implement development projects. World Bank projects and operations are designed to support poverty reduction strategies in low- and middle-income countries. However, it is clear that the level of satisfaction with funded projects varies from one project to another. Moreover, the search for investment performance is at the center of concerns in order to optimize financing for development benefits. According to the World Development Indicators from the World Bank (2020), the net PDA received by Sub-Saharan Africa has declined overall since 2011 as shown in Figure 1. 
ISSN 2582-2292

Vol. 3, No. 05 Sep-Oct; 2021

Graph 1: Evolution of net PDA received in Sub-Saharan Africa per capita and as a ratio of gross national income (GNI) from 2011 to 2018

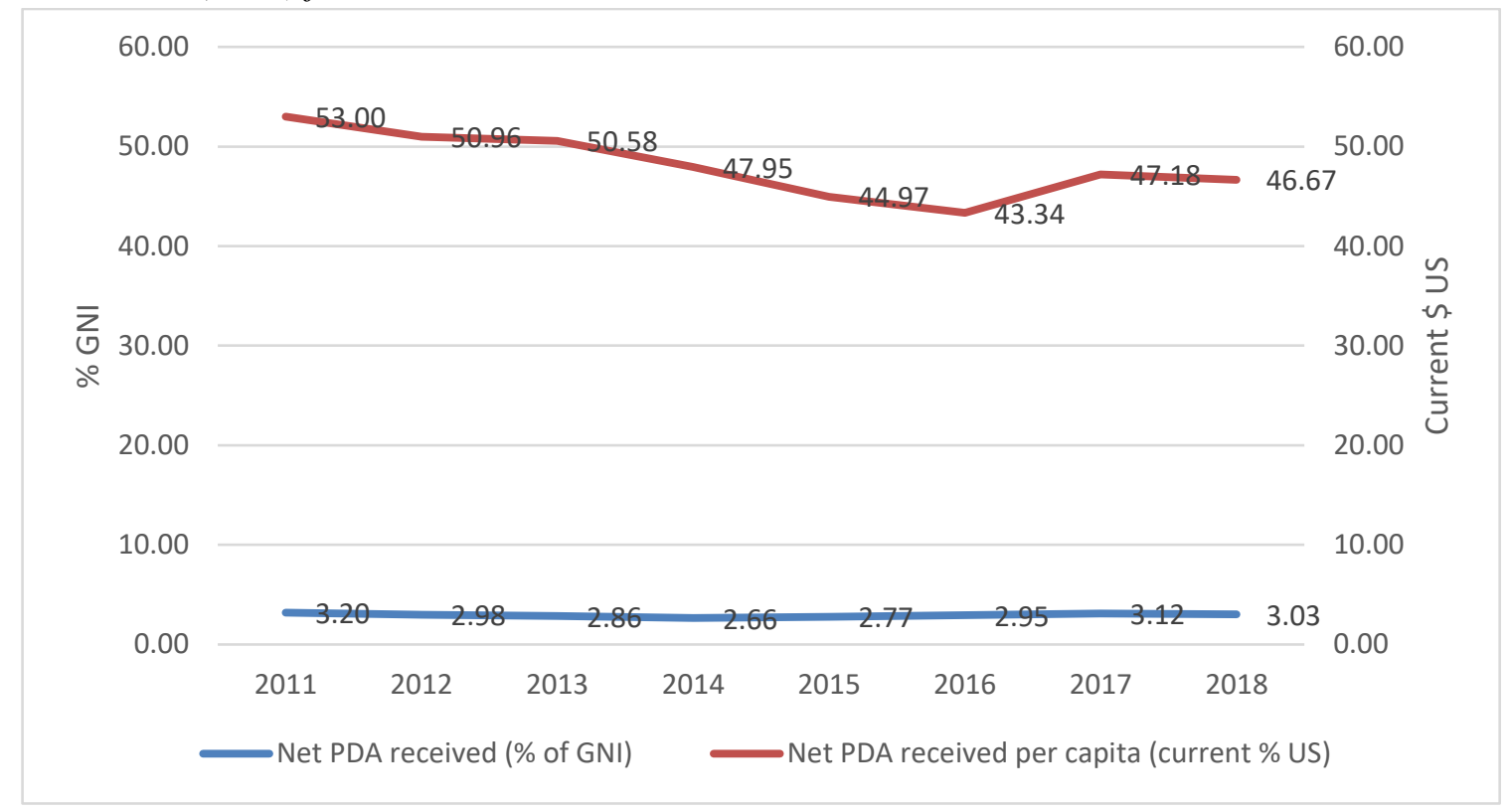

Source: WDI, World Bank (2020)

Figure 1 shows that net PDA received by Sub-Saharan Africa per capita increased from \$ 53 US in 2011 to $\$ 46.67$ US in 2018. Likewise, net PDA received by Sub-Saharan Africa as a ratio of gross national income increased from $3.20 \%$ to $3.03 \%$ over the same period. This downward trend calls for a critical assessment of development financing and its use in Africa. Thus, to contribute to the success of the implementation of development projects, it is necessary to identify the main axes of the projects which constitute the vectors used to provide development aid. This makes it possible to identify the main factors that promote the achievement of development results in projects, in particular public investment projects. Indeed, to consolidate their economies, several countries, mainly those in the process of development, have embarked on public investment projects. However, two countries can allocate the same budgets to capital expenditure, but the impact of these investments can differ significantly from one country to another. Hence, for a better return on investment, it is important to rationalize public investments by carrying out an assessment of their quality. Priority should be given to the quality of these investments rather than their volume.

In order to assess the quality of investments, our study looks at the performance of public investment projects financed by the World Bank in the 8 countries of the West African Economic and Monetary Union ( WAEMU ) that are Benin, Burkina Faso, Ivory Coast, Guinea Bissau, Mali, Niger, Senegal and Togo. These countries have implemented development plans and strategies in which public 
investment is an axis for increasing economic growth ( Hounsou 2017 ).

According to the results of the evaluation of the performance of public projects financed by the World Bank ( IEG World Bank Project Performance Ratings,,2020), from 1960 to 2019, it appears that 34\% of projects are below the satisfaction threshold in the WAEMU zone ( $3 \%$ very satisfactory, $21 \%$ moderately satisfied, $42 \%$ satisfied, $21 \%$ dissatisfied, $12 \%$ moderately dissatisfied and $1 \%$ very dissatisfied ). As this high rate of non-performing projects cannot be without justification, we look at the factors that explain this poor performance. The performance of projects in the WAEMU zone has therefore been influenced by factors that may be project-specific or country-specific.

Investment is considered as a key to economic growth and the fight against poverty ( Hounsou 2017, 2019). Just as much as the quantity of investments, whether public or private, it is important to look at the quality of the investments. This study makes it possible to assess the internal and external factors that influence the performance of public investment projects financed by the World Bank in the WAEMU countries over the period 2002 - 2019. It highlights the variables to be taken into account in order to create favorable conditions to obtain a better performance. Thus, the quality of the determinants of the performance of these projects makes it possible to reinforce the quality of investments in the Union, to build investor confidence and to promote economic prospects in these countries.

Finally, the rest of the study is organized as follows: section 2 deals with the literature review, section 3 presents the methodology adopted, section 4 analyzes the results and section 5 concludes the work.

\section{LITERATURE REVIEW}

\subsection{Theoretical review}

Performance is defined as a remarkable achievement or success in any area. Do a work in a short time is a real achievement. For Neely and al. (1995) performance must be apprehended through three angles: the quality, the time and the cost. Quality performance is seen as a compliance with technical specifications set for the production of a good or service. Performance with respect to the time is presented as the completion and execution of contracts with clients on time. The performance in the costs consists in their control so as to produce less expensively. Authors like Lorino (1996), Hauser and Katz (1998), Melnyk (2004) and Ariely (2010) argue that the performance exists and makes sense only if it is measured despite its form (global or local, financial, technical or economic, environmental, societal, absolute or relative).

In general, public investment refers to investment expenditure in physical infrastructure (roads, public buildings, etc.) and intangible infrastructure (innovation, research and development, etc.) with a productive lifespan of more than one year. Public investment includes direct and indirect investment. 
Hirschman (1958) defines public investment as the goods and services that make economic activity possible. Public investments consist of investments in social infrastructure whose function is to maintain and develop human capital (such as education, social and health services) and investments in economic infrastructure whose characteristic is to participate in the productive process. More precisely, public investment is the Gross Fixed Capital Formation (GFCF) carried out by public administrations.

Investment projects include the construction of new buildings, hospitals, roads, power plants, water reservoirs and other infrastructure items; replacement of old facilities; renovation of existing facilities; the acquisition of new facilities. Other projects may aim to develop or protect natural resources, increase the production of goods or services or create protection against certain natural hazards. Public investment projects normally consist of large one-time expenditures which may involve multi-year funding. In addition, their operation and maintenance creates future commitments (for funding of operation and maintenance) which must be estimated before making the decision to go ahead. The lack of funding for recurrent costs leads to project failures which imply a net loss of resources for the concerned country.

\subsection{Empirical review}

Numerous empirical studies have highlighted the determinants of project performance. Belassi and Tukel (1996) tried to determine the factors likely to influence the performance of projects in the literature. They distinguished between factors relating to the project (its size), those relating to the project team (skills), its organization and the external environment. In their econometric analysis Mubila et al. (2000) studied the success factors of projects financed by the African Development Bank during the pre-1995 period. This analysis covered a sample that comprises 146 projects. They used a probit model to determine project success factors. The results of this research show that a good economic environment, measured by economic growth rates, inflation and the level of development of the country, is an important factor in the success of a project. These results also highlighted certain specific characteristics of projects which are important determinants of their success, specifically the size and sector of the project.

In the same vein, Denizer et al. (2011) measured the statistical correlations between the performance of a project and its determinants. The study focused on a sample of 6000 projects financed by the World Bank between 1983 and 2009. It took into account the microeconomic determinants such as the size of the project, the sector of activity and the duration of the project but also the macroeconomic determinants such as the quality of economic policies and institutions. The results of the study indicated that the success of funded projects varies considerably both within and between countries. More precisely, it emerges that the size of the projects, the extent of the supervision of the project and the delays in the evaluation largely explain the intra-country heterogeneity which is relative to the 
success of the projects. Also, in countries with better policies and institutions, aid is relatively more effective, since the success rate of projects in these countries is also relatively higher.

Also, Bulman and al. (2015) examined the microeconomic and macroeconomic correlations of 3.821 aid projects financed by the World Bank and 1342 projects of the Asian Bank of Development from a probit model. The estimation results obtained from macroeconomic variables (country growth, political environment) and microeconomic variables (the short duration of the project, the presence of additional financing) have shown a positive influence on the success of the projects.

Chauvet and al. (2010) studied the effectiveness of transfers granted to emerging countries from a period of conflict (political instability, civil war, etc.). This effectiveness is judged by the success of the projects financed by these transfers. The results highlighted the prevalence of peace as a factor that positively affects the likelihood associated with project success. More specifically, the authors documented that, during post-conflict periods, projects related to the transport and urban development sectors were more successful. In addition, projects related to the education sector are less efficient and require more targeted supervision efforts. Also, results indicated the importance of time in the implementation of a project. The longer this time exceeds what is expected, the lower the probability of success. Finally, the authors underlined the importance of adequate preparation and supervision as the factors that significantly and positively affect the probability of a project's success.

In the same vein, Limodio (2011) examined the predictors of successful infrastructure projects conducted in several countries and financed by the World Bank. These projects covered the period 1979-2008 and concerned 1,912 projects. Among the control variables used in this study, we find the normalized average size of the project, the gross domestic product per capita, the infrastructure index, an index allowing to qualify the political system (democracy versus a dictatorial regime), governmental stability, the quality of institutions (transparency of administrations, efficiency of the judicial system), the level of corruption, ethnic tensions, as well as external conflicts. The results of this study revealed that the success of infrastructure projects depends mainly on the quality of their implementation.

Also, Blum's (2014) research focused on data from a large sample of World Bank public sector management projects that were approved between 1990 and 2013. The research contributed to an emerging literature that uses cross-country regressions to analyze models of public sector management reform. The results suggested that political context factors have a greater impact on the performance of public sector projects than on other projects. More specifically, public sector management projects perform better in countries with democratic regimes than in countries with autocratic regimes.

Alcazar and Wachtenheim (2000) analyzed the determinants of project success in Latin America based 
on a sample of 570 projects financed by social funds. The results of their study revealed that community participation, the level of education of the grassroots communities, the level of organization of the beneficiary populations are, among others, the determining factors of the performance of projects. These results were supported by the research work of Antwi and Oladele (2013) concerning the analysis of the effects of certain socio-economic factors on the performance of 47 agriculture projects in South Africa using a tobit model, which resulted in to the conclusion that, among other things, the level of education of beneficiaries, their experience, the political stability of the country where the project is located exert a significant influence on the performance of the projects.

All in all, these literatures underline the relative importance of specific project characteristics (design, size, duration, sector, scope of project supervision, and also the presence of additional funding), as well as that of factors affecting the project, that is the macroeconomic environment of countries, such as the effectiveness of economic policies, the institutional capacity of each country, monitoring efforts, level of education of beneficiaries, community participation, level of corruption, ethical tensions, political stability and social peace. However, it is of utmost importance to mention that the existing studies have not focused on projects conducted exclusively in the WAEMU countries. Thus, to the best of our knowledge, our study makes a significant empirical contribution by focusing on projects financed by the World Bank only in WAEMU countries.

\section{METHODOLOGY}

\subsection{The empirical model}

The empirical model develops the specification of the dependent variable, the specification of the independent variables and the specification of the model.

\subsubsection{Specification of the dependent variable}

The dependent variable or explained variable of our study measures the ex-post assessment of projects. This is a qualitative variable whose value varies from 1 to 6 according to the World Bank classification (1- very dissatisfied; 2- moderately dissatisfied; 3- dissatisfied; 4- satisfied; 5- moderately satisfied and 6- very satisfied).

\subsubsection{Specification of the independent variables}

The independent variables called the explanatory variables in our study are listed in two categories. The first category is specific to the specific characteristics of the projects studied, while the second category relates to the specific characteristics of the countries in which these projects were carried out.

There are three independent variables in the first category: the sector of activity, the duration of the project and the amount allocated for the realization of the project. 
Sector of activity: the nature of the projects studied in our work is very heterogeneous. Indeed, these projects are related to 15 sectors of activity, namely : (i) agriculture and rural development; (ii) economic policies ; (iii) education ; (iv) energy and mining ; (v) the environment; (vi) development of the financial and private sector ; (vii) global information / communications technologies ; (viii) health, nutrition and population ; (ix) poverty reduction ; (x) governance of the public sector ; (xi) the social development ; (xii) social protection; (xiii) transport ; (xiv) urban development ; and (xv) water.

The duration of the project: it corresponds to the actual number of years that have been devoted to the realization of a project. The raw database provides information on the year the project started as well as the year in which the project was completed. In order to identify the duration of the implementation of a project, we proceed by subtracting the last year from the first year.

The amount allocated to the project: it corresponds to the amount of money actually committed for the realization of the project. This is the initial amount granted which is revised after the end of the work. This variable is transformed into a logarithm in order to remove the effect of scale (the variables sector of activity and duration of a project are single-digit while the amount allocated is measured in millions of US dollars).

The second category of independent variables takes into account the growth rate of real GDP per capita, the level of corruption, political stability, government efficiency and the level of education. While the first variable is of an economic nature, those that follow refer to the institutional context that characterizes the countries in which the projects are implemented.

The growth rate of real GDP per capita: in our study, the economic environment is measured by the growth rate of real GDP per capita. The choice of this variable is justified first of all by the fact that studies concerning long-term economic growth are often based on this variable. Indeed, the latter allows a plausible economic comparison between countries, since it takes into account the differences in terms of the cost of living and demographic growth. Finally, this variable also allows a plausible comparison of the standard of living across countries, since it is positively correlated with phenomena closely related to the standard of living, such as life expectancy at birth and the level of education.

The level of corruption: is captured by an estimate of the control of corruption. Corruption control captures perceptions of the extent to which public power is exercised for private gain, including large and small forms of corruption, as well as the 'capture' of the state by elites and private interests. The estimate gives the score of countries on the aggregate indicator in units of a standard normal distribution that is to say, from about -2.5 to 2.5 . (W GI, 2020)

Political stability and absence of violence / terrorism: this variable measures the perceptions of the 
likelihood of political instability and / or politically motivated violence, including terrorism. The estimate gives the country's score on the aggregate indicator, in units of a standard normal distribution, ranging from about -2.5 to 2.5 . (W GI, 2020)

Government Effectiveness: it captures the perceptions of the quality of public services, the quality of the public function and its degree of independence from political pressures, the quality of policy formulation and implementation, and the credibility of the government's commitment to these policies. The estimate gives the country's score on the aggregate indicator, in units of a standard normal distribution ranging from about -2.5 to 2.5 (WG I, 2020).

From the macroeconomic point of view, the expected sign of all these variables is the positive sign.

\subsubsection{Model specification}

Since our study aims at determining the factors that influence the probability of success of projects and following some authors like Mubila and al. (2000), we note all the projects declared successful by 1 (very satisfactory, moderately satisfactory and satisfactory) and the remainder by 0 (unsatisfactory, moderately unsatisfactory and very unsatisfactory).

Since our explained variable (project performance) is dichotomous, we are forced to choose an appropriate and adapted analysis model. In this perspective, Hurlin (2003) underlines that the dichotomous models, logit and probit admit as an explained variable, not a quantitative coding associated with the occurrence of an event (as in the case of linear specification), but the probability occurrence of this event, conditional on the exogenous variables.

Historically, logit models were introduced as approximations of probit models allowing simpler calculations. Therefore, there are few differences between these two dichotomous models.

For the choice of our study model, we estimated the two models then compare the values of the AIC criteria of the latter. The value of the AIC criterion of a probit is less than that of a logit, which makes it possible to retain the probit model for the analysis explaining the ex-post assessment of the project Consider $\mathrm{Y}_{\mathrm{i}}$ the variable that measures the ex-post performance of a project.

More precisely:

$$
Y_{i}= \begin{cases}1 & \text { success } \\ 0 & \text { failure }\end{cases}
$$

We consider that the achievement of each of the contingencies (the ex-post performance of a project) depends on the ex-ante performance $\left(Y_{i}^{*}\right)$ of this project, which could be below or above a 
certain threshold $\left(l_{i}\right)$. This ex-ante performance is a latent variable (not observable and ongoing) that depends on a number of variables $\left(X_{i}\right)$ such as the characteristics of a project (the sector of activity, duration and volume of investment) and the specific characteristics of the country (the level of corruption, political stability and absence of violence, the level of education, the efficiency of government and the growth rate of real GDP per capita). Thus, the econometric model is presented as follows:

$$
Y_{i}=\left\{\begin{array}{lr}
1 & \text { si } Y_{i}^{*} \geq l_{i} \\
0 & \text { if not }
\end{array}\right.
$$

where,

$$
Y_{i}^{*}=X_{i} \beta+\mu_{i}
$$

and

$$
\mu_{i} \sim N\left(0, \sigma^{2}\right)
$$

The model we propose is partially observable, which is consistent with the phenomenon, studied in the context of our research since the performance of a project is a phenomenon that is not fully observable.

\subsection{Estimation of the model}

Before we estimate the parameters of the model ( $\beta$ and $\sigma$ ), it is first necessary to establish the likelihood of each of the contingencies for each of the observations $(N)$. Analytically, it is possible to verify that the probability of occurrence of each of the contingencies is written as follows:

$$
\begin{gathered}
P\left(Y_{i}=1\right)=P_{i}=1-F\left(\frac{\mathrm{li}-\mathrm{Xi} \beta}{\sigma}\right) \\
\text { and }
\end{gathered}
$$

It should be remembered that $F\left(\frac{\mathrm{li}-\mathrm{Xi} \beta}{\sigma}\right)=\int_{-\infty}^{\frac{\mathrm{li}-\mathrm{Xi} \beta}{\sigma}} \frac{1}{\sqrt{2 \pi}} e^{\frac{-t^{2}}{2}} d t$ corresponds to the distribution

function when the error term is normally distributed. Finally, the likelihood function of the model is established as follows:

$$
L=\prod_{Y_{i}=1} P_{i} \prod_{Y_{i}=0}\left(1-P_{i}\right)
$$

To estimate the probit model, we use the maximum likelihood method which is the most widely used. 
To validate the relevance of our regression results, certain tests must be used including the hypothesis tests on the parameters and the model prediction test. Also, certain criteria must be respected to decide on its optimality.

These tests aim to verify the significance of one or more coefficients in the model, that is to say, to evaluate the individual contribution of an explanatory variable or the overall significance of the model (Hurlin, 2003). The tests that can be used to judge the significance of the coefficients are the Wald test, the maximum likelihood ratio test, and the Lagrange multiplier test. Hurlin (2003) argues that these three tests are asymptotically equivalent but may contradict on small samples and that the Wald and maximum likelihood ratio tests are the most convenient on small samples.

\section{Likelihood ratio test}

This test is used to assess the overall significance of the model. The assumptions underlying the test are as follows:

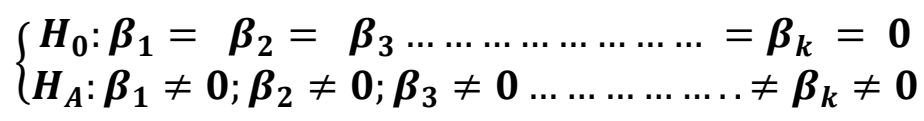

The null hypothesis $\left(H_{0}\right)$ is such that all the coefficients associated with all the explanatory variables are jointly zero. Therefore, the ex-post project performance becomes totally stochastic and the estimated model is generally not statistically significant. However, under the alternative hypothesis $\left(H_{A}\right)$ the expected values of these coefficients are not zero, which implies that the estimated model is globally and statistically significant.

This test also allows us to assess the individual significance of a coefficient. In doing so, we examine the following two hypotheses:

$$
\left\{\begin{array}{l}
\boldsymbol{H}_{\mathbf{0}}: \boldsymbol{\beta}_{i}=\mathbf{0} \\
\boldsymbol{H}_{\boldsymbol{A}}: \boldsymbol{\beta}_{i} \neq \mathbf{0}
\end{array}\right.
$$

The null hypothesis $\left(H_{0}\right)$ suggests that the coefficient associated with the explanatory variable $i$ is zero. Thus, the marginal effect of this variable on the ex-post performance of a project is not statistically significant. Moreover, under the alternative hypothesis $\left(H_{A}\right)$ this effect is statistically significant since the value of the parameter , which relates the explanatory variable to the ex-post performance of the projects (explained variable), is non-zero. 


\section{Test of prediction for the model}

The purpose of this test is to judge the goodness of fit, that is the fit of the model to the available data (Hurlin, 2003). It is a question of whether the specified model is a good tool of prediction of the determinants of the relevance of projects implemented by the World Bank.

\subsection{Characteristic data}

The data used in our study are of annual frequency and broadly cover the period from 2002 to 2019 for the eight WAEMU member countries due to a lack of data beyond the period. They come from three different databases of the World Bank (2020). It should be noted that the data relating to the dependent variable of the study and to the specific characteristics of the projects considered come from the IEG World Bank Project Performance Ratings database. In addition, the data relating to the specific characteristics of the countries in which the projects are conducted come from two different databases.

The level of corruption, political stability and government effectiveness are provided by the Worldwide Governance Indicators (WGI, 2020)) database; the growth rate of real GDP per capita and the level of education are obtained from the database World Development Indicator $s$ (WDI, 2020) of the World Bank.

Data are recorded from a sample of 225 projects covering the period 2002- 2019, years in which the projects have been implemented and evaluated.

The database used for the study does not provide all the information. We can note for example the difference between the expected duration of the project and the actual period, the difference between the amount for the project and the actual amount, and the information on the project team. Also, for lack of information, the variable gross enrollment rate in primary could not be added to the model.

\section{RESULTS AND ANALYSIS}

\subsection{Descriptive analysis}

Table 1 presents the results of the 15 sectors of intervention of the World Bank in the WAEMU countries as a whole. The results for each country are available and can be obtained on demand. On average, $66 \%$ of the projects evaluated were successful against $34 \%$ of failure. Sector 9 (poverty reduction) has the lowest success rate (40\%) against a success rate of over $50 \%$ for other sectors of activity. Sectors 7 (world technologies information s/ communications), 10 (public sector governance) and 11 (social development) have a 100\% success rate. We find that the average duration of projects varies between 0.42 and 7.82 years. The shortest average duration ( 0.42 years) corresponds to the poverty reduction sector and the longest average duration corresponds to the transport sector with the highest average cost of nearly $\$ 171$ million US. The lowest average cost concerns the 
environmental sector for nearly \$11 million US.

Table 1: Performance, duration and cost results by sector in the WAEMU countries

\begin{tabular}{lcccc}
\hline Sector & $\begin{array}{c}\text { Success } \\
(\%)\end{array}$ & $\begin{array}{c}\text { Failure } \\
(\%)\end{array}$ & $\begin{array}{c}\text { Duration } \\
\text { in years }\end{array}$ & $\begin{array}{c}\text { Lending Project } \\
\text { Cost in \$ US }\end{array}$ \\
& & & & \\
\hline 1: Agriculture and rural development & 51.72 & 48.28 & 5.60 & 44811085.86 \\
2: Economic policies & 64.00 & 36.00 & 0.65 & 59664000.00 \\
3: Education & 61.90 & 38.10 & 4.92 & 58423809.52 \\
4: Energy and mining & 62.50 & 37.50 & 6.56 & 69965187.50 \\
5: Environment & 66.67 & 33.33 & 5.95 & 10901291.67 \\
6: Financial and private sector & 58.33 & 41.67 & 6.55 & 33687500.00 \\
development & 100.00 & 0.00 & 5.25 & 15000000.00 \\
7: World & & & & \\
Technologies s information s / & 73.91 & 26.09 & 5.64 & 27628260.87 \\
communications & & & & \\
8: Health, nutrition and population & 40.00 & 60.00 & 0.42 & 52156632.00 \\
9: Poverty reduction & 100.00 & 0.00 & 3.90 & 22437500.00 \\
10: Public sector governance & 100.00 & 0.00 & 6.79 & 113680000.00 \\
11: Social development & 60.00 & 40.00 & 4.98 & 41039000.00 \\
12: Social protection & 50.00 & 50.00 & 7.82 & 170650000.00 \\
13: Transport & 50.00 & 50.00 & 6.18 & 61586666.67 \\
14: Urban development & 50.00 & 50.00 & 4.92 & 19812500.00 \\
15: Water & & & & \\
\hline
\end{tabular}

Source: Author's calculations

Table 2 shows the frequencies of investment projects benefited by the WAEMU countries. The information in Table 2 indicates that Burkina Faso and Senegal have generally benefited from more investment projects than the other countries. In addition, Guinea Bissau and Togo have benefited from fewer investment projects financed by the World Bank. As for the frequency of performance, Table 2 shows that with the exception of Burkina Faso, the performance of projects is generally well appreciated and is above $50 \%$ success rate. Togo achieves the best success rate of $92.31 \%$. 
ISSN 2582-2292

Vol. 3, No. 05 Sep-Oct; 2021

Table 2: Frequency s performances and projects by country

\begin{tabular}{lccc}
\hline Country & Success $(\%)$ & Failure $(\%)$ & $\begin{array}{c}\text { Frequency of } \\
\text { projects in\% }\end{array}$ \\
\hline Benin & 58.82 & 41.18 & 15.11 \\
Burkina-Faso & 45.65 & 54.35 & 20.44 \\
Ivory Coast & 58.82 & 41.18 & 7.56 \\
Guinea-Bissau & 76.92 & 23.08 & 5.78 \\
Mali & 53.57 & 46.43 & 12.44 \\
Niger & 60.00 & 40.00 & 13.33 \\
Senegal & 70.45 & 29.55 & 19.56 \\
Togo & 92.31 & 7.69 & 5.78 \\
\hline
\end{tabular}

\section{Source: Author's calculations}

\subsection{Empirical analysis of the results}

\subsubsection{Model validity}

The results of the probit model estimation are summarized in Table 3 and details are presented in Appendix 3. The statistic (Prob.> Chi $2=0.421$ ) indicates that the observed values are statistically significant at the $5 \%$ level. This means that the model is globally significant. In addition, our analysis model predicts a good quality rate of $64.44 \%$. This rate being greater than $50 \%$, then the specified model is a good tool for predicting the determinants of the relevance of the investment projects implemented by the World Bank in the WAEMU countries over the period of the study.

\subsubsection{Empirical analysis of the results}

The estimation of the model through the results of Table 3 shows that the sign of the coefficient associated with the variable duration of the project is positive as indicated by the macroeconomic theory and is significant at the $10 \%$ level. An increase in the duration of the project then induces an increase in the ex-post appreciation of the project. This result is confirmed by the study of Denizer and al. (2011). This result is justified by the fact that the longer the duration of a project, the more a self-learning mechanism (Learning-by- doing) is put in place, which makes it possible to correct the imperfections observed, thus improving the ex - post performance of the project.

The model also confirms that the sign of the parameter associated with the project cost variable is positive and significant at the $10 \%$ threshold. This result suggests that the higher the cost of the project, the better the performance of the latter. This result is consistent with the predictions of the study by Denizer et al. (2011) who suggests that the size of a project measured by the amount allocated to the 
project greatly determines the success of the latter.

The estimation of the model allows us to conclude that the performance of projects is higher in a less corrupt context since the coefficient relating to the corruption level variable is positive and significant at the $10 \%$ level. This result is in line with the study by Limodio (2011) for whom the level of corruption influences the success of infrastructure projects carried out in several countries with funding from the World Bank.

The signs of the variables government effectiveness and political stability and absence of violence / terrorism are positive showing a positive effect on the performance of projects. Thus, the more efficient the government, the more efficient the project. Also, the performance of projects is higher in a stable political environment without violence / terrorism. These results are consistent with studies by (Chauvet and al., 2010; Limodio, 2011; Blum, 2014).

Concerning the macroeconomic environment variable on the ex-post assessment of projects through the growth rate of real GDP per capita as an explanatory variable, the results of this estimate show that the sign of the coefficient of this variable is positive and significant at the threshold of $10 \%$. Thus, economic growth positively affects the performance of a project. This same result has been demonstrated by several studies ( Mubila and al., 2000 ; Denizer and al., 2011 ; Bulman and al., 2015). Overall, our study empirically suggests that the performance of a project depends on its own intrinsic factor, but also in the economic environment and institutional.

Table 3: Results of the estimation of the probit model

\begin{tabular}{lcc}
\hline Variables & Coefficients & Empirical significance \\
\hline Duration in years & 0.062 & 0.055 \\
LendingProjectCost & $1.20 \mathrm{E}-09$ & 0.076 \\
Sector code & 0.031 & 0.014 \\
Level of corruption & 0.735 & 0.058 \\
Government effectiveness & 0.909 & 0.009 \\
Political stability and absence & 0.047 & 0.796 \\
of violence / terrorism & & 0.079 \\
GDP growth rate & 0.436 & \\
\hline
\end{tabular}

Source: Author's calculations

\section{CONCLUSION}

The objective of our study was to analyze the factors explaining the performance of investment projects financed by the World Bank in the WAEMU countries. In doing so, assumptions were made on a number of variables relating to the projects and the characteristics of the project environment were identified. It was to analyze the effect of the intrinsic characteristics to the project on the project 
performance level and to assess the impact of factors related to the countries (economic and institutional) on the performance of projects. A descriptive analysis and an econometric analysis based on the estimation of a probit model were developed.

Based on data for 225 projects over the period 2002-2019 in the WAEMU countries, we came to the conclusion that the estimated probit model is globally and statistically significant .According to the study, we conclude that the project-specific factors (duration, sector and amount allocated), the institutional environment (level of corruption, government effectiveness, political stability and absence of violence, terrorism ) and the economic environment (growth rate of GDP per capita) have a positive effect on the ex - post performance of the investment projects financed by the World Bank in the WAEMU countries. More precisely, it emerges that the performance of projects is influenced by the duration of the project, the amount allocated to the project, the nature of the projects, the efficiency of the government and the growth rate of real GDP per capita.

Moreover, if we consider the results of this study, an improvement in the economic environment and the institutional framework of the union would help increase more projects performance. It would therefore be interesting to orient new projects in the countries with favorable environmental conditions, but also to create these conditions in disadvantaged countries. Also, these results suggest to the investors, in particular the World Bank, that the longer duration of a project makes it possible to make adjustments which improve the performance of projects and that the large-scale projects are the most efficient.

Our study has the advantage that, to the best of our knowledge, it is the very first to analyze the effectiveness of investment projects financed by the World Bank in the WAEMU countries. However, the unavailability of information on certain macroeconomic data on the concerned countries, as it is often the case for developing countries, has led us to limit the choice of our macroeconomic variables. Other subsequent studies may meet the challenge in order to contribute to the literature.

\section{REFERENCES}

Alcazar, L. and Wachtenheim, E. (2000)). "Determinants of Success of Social Fund Projects: The Case of FONCODES) ". Instituto Apyao, Lima

Antwi , MA and Oladele , I. (2013). "Determinants of Performance of Land Redistribution for Agricultural Development (LRAD) Projects in the Ngaka Modiri Molema District, South Africa". Journal of Human Ecology, vol.42, no.2, p.155-162.

Ariely D. (2010). "You Are What You Measure". Harvard Business Review Vol.88, no.38, 
Belassi , W., and Tukel, O. I. (1996) . "A New Framework for Determining Critical Success / Failure Factors in Project" International Journal of Project Management, vol.14, no.3, p. 141-151.

Blum, JR, (2014). "What Factors Predict How Public Sector Projects Perform? A Review of the World Bank's Public Sector Management". Working Paper No. 6798, Washington, DC, World Bank, 59p.

Bulman, D., Kolkma, W., Kraay, A. (2015). "Good Countries or Good Projects? Comparing Macro and Micro Correlates of World Bank and Asian Development Bank Project Performance". Working Paper No. 7245, Washington, DC, World Bank, 29p.

Chauvet, L., Collier, P. and Duponchel , M. (2010 ). "What Explains Aid Project Success in Post - conflict Situations? " Working Paper No. 5418, Washington, DC, World Bank, 28p.

Denizer, C., Kaufmann, D. and Kraay , A. (2011). "Good Countries or Good Projects? Macro and Micro Correlates of World Bank Project Performance". Working Paper No. 5646, Washington, DC, World Bank, 36p.

Hauser, JR., Katz, G. M. (1998). "Metrics: You Are What You Measure". European Management Journal, Vol.16, no.5 pp. 517-528.

Hirschman, A. O. (1958). "The Strategy of Economic Development". Canadian Journal of Economics and Political Science Vol 27, no 1, pp. 110 - 112.

Hounsou , R. (2019). "Comparative Analysis of the Determinants of Private Investment in WAEMU and CAEMU Zones". International Journal of Management and Economics Invention. Flight. 5, Issue 11, pp 2126-2136.

Hounsou , R. (2017). "Analysis of Public Investment Expenditure on Economic Growth in WAEMU Countrie"s. International Journal of Business and Management Invention. Flight. 6, Issue 5, pp49-67.

Hurlin, C. (2003). "Economics of Qualitative Variables". Masters in Econometrics. University of Orleans.

Limodio, N. (2011). "The success of Infrastructure Projects in Low-income Countries and the R ole of S electivity". Document Work No. 5694, Washington, DC, Bank World, 35p. 
Lorino , P. (1996). "Performance Methods and Practices". Organizational Editions.

Mubila , M. M, Lufumpa , C. and Kayizzi - Mugerwa , S. (2000). "A Statistical Analysis of Determinants of Project Success: Examples from the African Development Bank". Economic research papers $\mathrm{N}^{\circ} 56$, The Africa Development Group, Tunis, Tunisia, 18p.

Melnyk, S. A., Stewart, D, Swin, M. (2004). "Metrics and Performance Measurement in Operations Management: Dealing With the Metrics Maze". Journal of Operations Management, 22 (3), 2004, pp. 209-218.

Neely, A., Gregory, M., Platts, K. (1995). " Performance Measurement System Design: A Literature Review and Research Agenda". International Journal of Operations and Production Management, Vol. 15, no 4, pp. 80-116. 